ASEPTIC NECROSIS OF BONE IN TRANSPLANTED CHILDREN. $M$. Lazarus, ${ }^{\star} H$. Watts, ${ }^{\star}$ E. Lowrie ${ }^{\star}$ R. Levey, ${ }^{\star}$ and W.E. Grupe. Children's Hosp. Med. Ctr., Boston, Mass

Aseptic necrosis (AN) of bone was evaluated in 19 renal transnlant ( $\mathrm{Tx}$ ) patients (ages 3-17 yrs.). Two were excluded because of early death. The average time from recognition of renal failure to $\mathrm{Tx}$ in the remaining 17 patients $(6 \mathrm{M} ; 11 \mathrm{~F}$ ) was 26 mos. Four had minimal $\mathrm{X}$-ray evidence of hyperparathyroidism prior to $\mathrm{Tx}$ but none of the 17 had a parathyroidectomy nor received Vitamin $\mathrm{D}$ or calcium before or after $\mathrm{Tx}$.

With post-Tx follow-up of 6-28 mos., 6 of 17 (358) had symptoms and $\mathrm{X}$-ray findings of $\mathrm{AN}$. The average duration between $T X$ and onset of symptoms and positive $X$-ray findings was 5.5 mos. and 7.6 mos. respectively (range 1-15 mos.). All patients had involvement of 2 or 3 weight bearing joints.

Presence of AN was related to duration of recoonized renal failure before $\mathrm{Tx}(\mathrm{p} \angle \mathrm{Q} .001)$. The average ace at $\mathrm{TX}$ in those with AN was 14.5 yrs., while in those without AN was 11.5 yrs. $(\mathrm{p}<0.05)$. Five patients, never receiving a high dose I.V. methylprednisolone (MP) "pulse" for rejection, had no AN; 6 of 12 who were "pulsed" developed AN (p<0.07). The following were found not to be correlated with AN: previous hypernarathyroidism, time on dialysis, prednisone before $\mathrm{Tx}$ (4 nts.), or toeal dosage of prednisone post-Tx.

AN has been the major morbidity in this $\mathrm{Tx}$ population. Evidence suggests that AN in children is related to the duration of uremia, development of puberty, and to the number of IV MP "pulses", but not total dosage of steroids.

EFFECT OF GESTATIONAL AND POSTNATAL AGE ON GLOMERULAR FILTRATION RATE (GFR) AND TUBULAR MAXIMA OF GLUCOSE ( $\mathrm{TmG}_{\mathrm{G}}$ ) IN HUMAN INFANTS. Rosemary D. Leake and William Oh. Dept. of Ped., UCLA Sch, of Med., Harbor Gen. Hosp., Torrance, Cal if.

Twenty-four heal thy newborn infants with gestational ages ranging from 26 to 42 weeks were studied at 2 days to 9 weeks postnatal age to evaluate the rate of glomerular and tubular maturation. Glomerular function (GFR) was assessed by inulin clearance and tubular function by $T \mathrm{~m}_{\mathrm{G}}$. Birth weights of the study infants were appropriate for gestational age. The GFR of $\mathrm{fifteen} 2-3$ day old infants ranges from 17 to $101 \mathrm{ml} / \mathrm{min} /$ $1.73 \mathrm{~m}^{2}$ and is directly related to gestational age $(r=0.829)$. The $\mathrm{Tm}_{\mathrm{G}}$ of fifteen $2-3$ day infants ranges from 14 to $149 \mathrm{mg} /$ $\mathrm{min} / 1.73 \mathrm{~m}^{2}$ and is also directly proportional to gestational age $(r=0.710)$. Serial studies showed extrauterine renal maturation occuring at the same rate as intrauterine. The $T \mathrm{~m}_{\mathrm{G}} /$ GFR ratio did not change significantly with postnatal age (mean $=1.29+0.08$ S.E.M. in the first $2-3$ days and $1.27+0.17$ S.E.M. after 3 days). These data show that the development of glomerular and tubular function in utero is consistent with morphologic maturation, and that following birth, maturational renal changes proceed in a balanced, appropriate direction.

THE KININ-GENERATING SYSTEM IN LIPOID NEPHROSIS. SOO K. Le and Ronald J. Kallen. Univ. of Chicago-Pritzker Sch. of Med., Dept of Ped, La Rabida Children's Hosp. and Research Ctr.. Chicago. (Intro. by Samuel Spector).

Al tho the etiologic incitant of "lipoid nephrosis" is not known, it is likely that a host mechanism mediates the glomerular permeability changes. As a first step in examining the role of the kinin-generating system, plasma prekallikrein was assayed by means of its esterolytic action on a synthetic substrate. Kallikrein inhibitor was quantitated in arbitrary units. The results in 19 children, during an overt nephrotic episode (Active) and after corticosteroid-induced remission are given in the table:

$\begin{array}{llll}\text { Prekallikrein } & \frac{\text { Active* }}{0.4 \pm 4.45} & \frac{\text { Remissiont }}{19.3 \pm 3.97} & <0.001 \\ \text { Kallikrein Inhib. } & 0.47 \pm 0.06 & 0.76 \pm 0.04 & \mathrm{P}\end{array}$

$*$ Values in 11 normal subjects were: prekallikrein $99.6 \pm 2.9$ moles $/ \mathrm{ml} / \mathrm{hr}$; kallikrein inhibitor, $0.94 \pm 0.04$ units (mean \pm ( S.E.M.)

After cessation of corticosteroids in 11 patients, plasma pre kallikrein was $100.4 \mu \mathrm{moles} / \mathrm{ml} / \mathrm{hr}$.; and kallikrein inhibitor, 0.84 units. Conclusions: 1)Plasma prekallikrein and kallikrein inhibitor are depressed during the active nephrotic syndrome but rise toward normal during remission; 2)Kinins may be the host mechanism mediating increased glomerular capillary permeability. Studies of urinary kallikrein are currently in progress.
Effects of Intravenous Furosemide (F) on Renal Functions in Children with Nephrosis. Peter R. Lewy ${ }^{*}$ (Introduced by Henry L. Nadler), Dept. of Pediatrics, Northwestern Univ. Medical School. Children's Memorial Hospital, Chicago.

Clearances of inulin $\left(C_{I N}\right)$ and PAH $\left(C_{P A H}\right)$ were measured in 9 nephrotic children, aged $1 \frac{1}{2}$ to $14 \mathrm{yrs}$, before and after $\mathrm{F}$ $1 \mathrm{mg} / \mathrm{kg}$. All pts. had edema $\geq 15 \%$ dry body weight or $\geq 4.5$ 11ters. Serum albumin averaged $1.2 \mathrm{gm} \%$ (range $0.8-2.3$ ) urinary protein averaged $9.6 \mathrm{gm} / 24 \mathrm{hr} / 1.73 \mathrm{~m}^{2}(2.6-22.5)$

131 I- albumin plasma volume in 5 pts. averaged $113 \%(87-138)$ of "norma1" for dry welght. Effects of $F$ after two 30 minute control periods (C) are shown as averages and range of values corrected to $1.73 \mathrm{~m}^{2}$.

\begin{tabular}{|c|c|c|c|c|}
\hline & \multirow[b]{2}{*}{ C } & \\
\hline & & $0-15$ & $15-30$ & $\underline{30-60}$ \\
\hline $\mathrm{m} 1 / \mathrm{min}$ & $132(83-201)$ & 100 & $76(30-132)$ & 71 \\
\hline $\mathrm{PAH} \mathrm{ml} / \mathrm{min}$ & $587(403-890)$ & 712 & $464(280-808)$ & 386 \\
\hline 1. $\mathrm{ml} / \mathrm{min}$ & $0.64(0.44-0.99)$ & 9.0 & $12.2(7.2-17)$ & 4.6 \\
\hline VuM/ & $25(1.4-89)$ & 931 & $1245(166-1870)$ & 745 \\
\hline $\mathrm{VuM} / \mathrm{min}$ & $71(43-132)$ & 257 & $277(96-654)$ & 177 \\
\hline
\end{tabular}

Absolute urine volume in $60 \mathrm{~min}$. after $F$ averaged $323 \mathrm{ml}$ (115-800). Vital signs were stable but 3 pts. had transient abdominal cramping with $\mathrm{F}$ injection. Post diuresis serum $\mathrm{Na}$ was stable at 131 while serum $\mathrm{K}$ fell from 4.1 to $3.4 \mathrm{mEq} / \mathrm{L}$. $F$ is an effective diuretic at low doses in nephrotic children but decrease in clearances suggests some caution in dose frequency.

CLASSTCAL (DISTAL) RENAL TUBULAR ACIDOSIS: ENDOGENOUS ACID PRODUCTION S In and J C M Chan. George Washington Univ Children's Hosp Nat Med Ctr, Washington, DC; Children's Hosp of Los Angeles. (Intr by Wellington Hung).

It has been shown by McSherry et al (C1in Res $21: 229,1973$ ), that children with classical (distal) renal tubular acidosis (CRTA) can achieve normal growth with sustained correction of acidemia by aggressive alkali therapy of up to $6-10 \mathrm{mEq} / \mathrm{kg} /$ day. To test the hypothesis that such patients have a marked increase in endogenous production of non-volatile, non-carbonic acid, incident to "catch-up" growth, three children aged 3-10 years with cRTA were each studied for three weeks by the methods of Relman et al (JCI 40:1621,1961) regarding the rate of endogenous acid production.

Mean values of patients and the twelve controls (in brackets) are presented in $\mathrm{mEq} / \mathrm{kg} /$ day: sulfuric acid production, $2.5 \pm 0.2(1.3 \pm 0.3)$; hydrogen ion production incident to incomplete oxidation of organic acid, $0.9+0.2$ $(1.0+0.4)$ and total net acid production, $3.4+0.2$ $(2.3 \mp 0.1)$. Stepwise increments of the bicarbonate therapy from $\overline{2}$ to $6 \mathrm{mEq} / \mathrm{kg} /$ day corrected the acidemia but did not alter the rate of endogenous acid production.

The data indicate that the rate of endogenous acid production in these children with cRTA is $30 \%$ higher than comparable, healthy children and the increased sulfuric acid production accounts, in large part, for this elevation. It is concluded that the metabolism of sulfur-containing amino acids is accelerated, the exact mechanism of which requires further study.

\section{PERMEABILITY CHARACTERISTICS OF THE RENAL TUBULE DURING} MATURATION. Earle A. Lockhart and Adrian Spitzer; Albert Einstein College of Medicine, Bronx, N.Y.

The use of inulin as a marker of GFR has been validated in adult, but not in newborn animals. As a consequence, the low values for GFR observed in early life could be artifactual from leakage of filtered inulin from the tubules. To test this, a microinjection study was performed in guinea pigs ranging in age from 2 to 90 days. The mean recovery of inulin (mol. wt, 5500) was $95.5 \pm 0.8$ (SE), $n=53$, and no variation was observed as a function of age. To test further the permeability characteristics of the tubule of the young animal, the recovery rates of substances $(S)$ with progressively lower molecular weights were compared to those of simultaneously injected inulin.

\begin{tabular}{lccr}
\multicolumn{1}{c}{$\mathrm{S}$} & Mol. Wt. & \% Recov. S & \\
\cline { 3 - 4 } \multicolumn{1}{c}{ \% Recov. In } & $\mathrm{n}$ \\
Mannitol & 342 & $.94 \pm .02$ & 12 \\
Creatinine & 180 & $.96 \pm .02$ & 13 \\
Glycerol & 113 & $.94 \pm .02$ & 13 \\
& 92 & $.66 \pm .07$ & 5
\end{tabular}

The slopes of the regressions of the recovery ratios as a function of age were not different from zero. We conclude that inulin is a valid marker of GFR in the newborn animal and that the permeability of the renal tubule for non-electrolytes is similar in the newborn and adult guinea pig. 